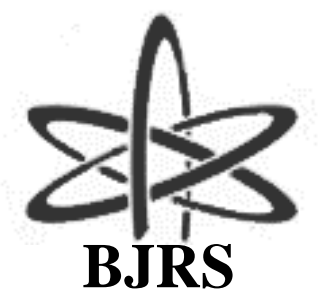

BRAZILIAN JOURNAL

$\mathrm{OF}$

RADIATION SCIENCES

09-01 (2021) 01-28

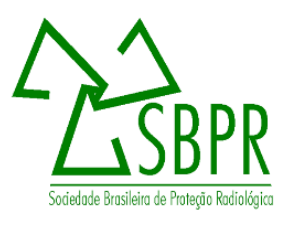

\title{
A simulation model for capacity planning of nuclear fuel plants for research reactors
}

\author{
Negro $^{a}$ M.L.N.; Durazzo ${ }^{a}$ M.; Mesquita $^{b}$ M.A.; Scuro ${ }^{a}$ N.L.; \\ Carvalho $^{\mathrm{a}}$ E.F.U.; Andrade ${ }^{\mathrm{a}}$ D.A. \\ ${ }^{a}$ Instituto de Pesquisas Energéticas e Nucleares (IPEN / CNEN - SP) \\ Av. Professor Lineu Prestes 2242 - 05508-000 São Paulo, SP, Brazil \\ mlnegro@ipen.br \\ ${ }^{b}$ Departamento de Engenharia de Produção - Escola Politécnica - Universidade de São Paulo \\ Av. Professor Luciano Gualberto, travessa $3 n^{o} 380$ - 05508-010 São Paulo, SP, Brazil
}

\begin{abstract}
The demand for nuclear fuel for research reactors is increasing worldwide. However, some nuclear fuel factories have low production volumes. Literature regarding how to expand the capacity of those facilities in a safe and reliable way is scarce. Thus, the purpose of this work is to propose and validate a conceptual model for increasing the production capacity of such factories. The facilities addressed here are those that produce plate-type fuel elements loaded with $L E U \mathrm{U}_{3} \mathrm{Si}_{2}-\mathrm{Al}$, which are typically used in nuclear research reactors. Data from a real nuclear fuel plant was collected and applied to the model, thus setting up a case study. Two different strategies, as well as several production scenarios, were conceived for the use of the model. Each scenario experiments with the different possibilities of enlarging capacity. Discrete events simulation was used in order to cover all production scenarios. The tests indicated significant increases in productive capacity, thus showing that the model fully achieved its proposed objective. One of the main conclusions to be highlighted is the model's effectiveness, which was demonstrated by using the model in two different strategies and obtaining increases in capacity with both of them.
\end{abstract}

Keywords: Factories of nuclear fuel, Nuclear research reactors, Productive capacity management. 


\section{INTRODUCTION}

\subsection{A brief note about the evolution of nuclear reactors}

Two of the main characteristics of all reactors where uranium fission occurs are neutron flux and heat production. The development of nuclear technology has led to two basic types of nuclear reactors. The first type focuses on neutron flux, while the second has the objective of producing heat [1]. A high neutron flux is necessary for research in nuclear science. It is for this reason that reactors with high neutron fluxes are called research reactors. On the other hand, the interest in heat led to the development of nuclear power plants in which nuclear heat is used to generate electrical energy. That is the reason why such reactors are called power reactors. The typical thermal power of nuclear power reactors ranges from 3,000 MW to 6,000 MW [2], while the thermal power of research reactors usually remains below $100 \mathrm{MW}$.

Approximately fifty years ago, scientists discovered that radiation could be beneficial in the treatment and diagnosis of some diseases. Some of the radiation types in question are produced in research reactors. Researchers also found that some components of medications had their efficacy increased when irradiated by a neutron beam. This was the way radiopharmaceuticals, drugs irradiated by neutrons or whose components were irradiated by neutrons, were born. The neutron flux present in research reactors is an important source of neutrons for the production of radiopharmaceuticals. The demand for nuclear medicine has grown continuously and at ever-greater rates [3], causing a much higher level of usage of nuclear research reactors than originally predicted.

Approximately thirty years ago, scientists also discovered that using neutrons to irradiate silicon, a key raw material for the manufacturing of integrated circuits and processors, increases the electrical conductivity of that element [4]. If a greater electrical conductivity is available, then a greater processing capacity of the mentioned components is achieved. The considerable increase in the use of computers and mobile phones further explains the great interest of the electronic industry in the use of nuclear research reactors [5].

Furthermore, research and teaching of nuclear technology have also grown in recent decades [6]. This growth has caused an increase in the use of nuclear research reactors because they are responsible for a considerable part of the generation and transmission of knowledge about nuclear technology.

Nuclear medicine, the electronic industry and nuclear research have provoked not only an increase in the use of nuclear research reactors, but also the need of higher neutron fluxes. Considerably higher neutron flows are only achieved with high reactor design power. For this 
reason, research reactors built in recent years have an average minimum thermal power of 20 MW, reaching up to $100 \mathrm{MW}$ [7]. The increase in the use and the power of nuclear research reactors in the last decades, in turn, has caused a growth in demand for their fuel [8].

\subsection{Increased demand}

Demand for nuclear fuel for research reactors has been driven by global players from countries in which nuclear technology is more developed, like the USA, France and Russia, among others. However, there are still some production facilities for this type of fuel whose productive capacity is insufficient to meet the demand of current research reactors. The increased demand therefore requires that some fuel manufacturing facilities expand their productive capacity. Naturally, capacity expansion must also maintain the safety of production processes and the quality of the final product. These facts lead to the establishment of the following research question: How can the production capacity of nuclear fuel factories for research reactors be increased safely and qualitatively?

The answer to this research question requires the application of knowledge from the area of production administration to the manufacturing of nuclear fuel for research reactors. Within the area of production management, focus should be on the dimensioning of manufacturing production capacity, which is usually done in a factory's project phase [9]. The concepts of this type of project also apply to modifications of existing factories, as is the case of some of the current nuclear fuel manufacturing facilities.

\subsection{Scope delimitations}

An adequate response to the research question demands some scope delimitations regarding nuclear fuel. The first one refers to the type of fuel, as there are several types of nuclear fuel for research reactors [10]. The fuel selected for this analysis is based on uranium silicide $\left(\mathrm{U}_{3} \mathrm{Si}_{2}\right)$, due to its good load capacity of uranium and excellent performance [11]. Besides, uranium silicide-based fuels are used in a considerable number of research reactors [12-14].

Another scope delimitation refers to the production route of $\mathrm{U}_{3} \mathrm{Si}_{2}$, as this fuel can be obtained through different processes [15]. The chosen route includes the hydrolysis of uranium hexafluoride $\left(\mathrm{UF}_{6}\right)$ for the following reasons:

- relative simplicity;

- production of small quantities of intermediate products, a fact that contributes to safety; 
- demand increase will likely also affect factories that use this production route;

- the data available for this work comes from an installation that uses this route.

From another perspective, there are few facilities that use the route of $\mathrm{UF}_{6}$ hydrolysis. This fact explains the scarcity of literature to guide the increase in capacity. This lack of specific literature also justifies the choice of the cited route for this analysis.

The last scope delimitation refers to the vector responsible for the availability of nuclear fuel in research reactors. The vector considered in this study is the typical plate type fuel element (FE) because this is the type of FE most commonly used in nuclear research reactors [16].

\subsection{Objective, originality and contribution}

The issue presented in [17] was extended in this work in order to contemplate a more efficient way of expanding production capacity. That extension led to the defining of the objective of this paper, which is to propose and test a conceptual model to expand the productive capacity of factories of typical plate type FE for nuclear research reactors which use $\mathrm{U}_{3} \mathrm{Si}_{2}$.

The originality of this study is due to a lack of scientific publications on this subject. Such a gap has been proven through searches in different data bases of scientific publications in the years from 2015 through 2017. Each database has its own initial date, that is, the date from which there was a record of scientific publications in that database. The period corresponding to the responses of the databases for the searches carried out in this work extends from the initial year of registration of each database until November 2015, October 2016 and April 2017, respectively. The consulted databases and the respective start year of recording scientific publications are listed below.

- American Nuclear Society - 1960

- International Atomic Energy Agency - 1957

- $\quad$ SCOPUS - Elsevier Publisher database - 1956

- Science Direct - 1947

- Web of Science - 1900

The databases were searched with expressions in the English language, aiming at a wider return of responses. Such expressions were set in the fields "title" and "topic or subject" in the search engines. Some of the expressions used for the cited searches are listed below:

- methods of capacity increasing for production of nuclear fuel using the hydrolysis of $\mathrm{UF}_{6}$ for research reactors; 
- methods of capacity increasing for production of nuclear fuel for research reactors;

- capacity planning of nuclear fuel for research reactors;

- production increase of nuclear fuel for research reactors;

- production of nuclear fuel for research reactors.

Several of the databases did return answers, but none of them matched the topic of this work. Most of the answers related to only a part of the subject, such as the detailed chemical part of $\mathrm{UF}_{6}$ hydrolysis or the optimization of fuel recharge in a PWR. Other databases, however, did not return any responses.

As for knowledge contribution, this work collaborates with the building of a scientific basis through the input of knowledge from the area of production administration as applied to the manufacturing of plate type $\mathrm{FE}$ containing $\mathrm{U}_{3} \mathrm{Si}_{2}$ for nuclear research reactors.

\section{LITERATURE REVIEW}

\subsection{Nuclear fuel}

The level of uranium enrichment present in the fuel of most research reactors corresponds to the concentration of $19.75 \pm 0.25 \%$ in mass of the isotope ${ }^{235} U$ [10]. This value is known as low-enrichment uranium (LEU). That fact led to the selection of LEU for the concentration of uranium in the fuel considered in this work. The density of uranium in the fuel was assumed to be $3.2 \mathrm{~g} / \mathrm{cm} 3$, given that it is the most common in nuclear research reactors [18].

The production process in focus includes grinding $\mathrm{U}_{3} \mathrm{Si}_{2}$ and mixing its powder with aluminum powder $(\mathrm{Al})$. This mixture of powders is pressed and wrapped in aluminum plates, with the resulting assembly being laminated. Thus, there is a considerable amount of aluminum in the vicinity of $\mathrm{U}_{3} \mathrm{Si}_{2}$ molecules. In this situation it is said that $\mathrm{U}_{3} \mathrm{Si}_{2}$ is dispersed in $\mathrm{Al}$ matrix. It is through this process that the nomenclature for the selected fuel of this work is derived: it is low-enrichment uranium silicide dispersed in aluminum matrix, commonly named $\mathrm{LEU} \mathrm{U} \mathrm{U}_{3} \mathrm{Si}_{2}-\mathrm{Al}$ [19].

For the purpose of this study it is considered that the final product of a nuclear fuel plant is a typical plate type FE. The function of this product is to provide nuclear fuel to research reactors. These are the main characteristics of a typical plate type FE [19]:

- there are about 20 flat fuel plates (FP) inside the FE;

- each FP is loaded with $\mathrm{LEU} \mathrm{U}_{3} \mathrm{Si}_{2}-\mathrm{Al}$; 
- there is room between the FPs for water circulation in order to refrigerate and for the moderation of neutrons.

\subsection{Production management}

The planning of productive capacity depends on decisions based on both organizational strategy and production strategy [20]. One of the key issues deriving from such decisions is the measurement of capacity [21]. A capacity measurement system, which varies from organization to organization and even within organizations, must be established. For example, the capacity can be measured by the inputs consumed as well as by the production volume [9]. The capacity measurement unit selected in this paper is the annual production volume in number of FE per year. The reasons for that choice are as follows:

i) the typical plate type FE is the product for which demand is increasing, and

ii) it is the final product of several nuclear fuel factories.

Another relevant issue for capacity planning is the bottleneck. The Theory of Constraints [22] predicts the approach of the bottleneck through two angles. The first one is the knowledge of the bottleneck itself, seeking to identify its nature, its characteristics and its functioning. The second angle is the analysis of the bottleneck's relation with other processes of the productive flow.

Moreover, the proper identification of the bottleneck can benefit from two ways of considering the production of a factory. These two ways are often referred to as micro, or specific, view and macro, or general, view [23]. The micro view looks at each process individually, whereas the macro view considers sets of processes, which can be grouped into manufacturing cells, work centers (WC), or simply according to affinity among processes [24]. In the search to identify the bottleneck, it is advisable to switch from between the micro view and the macro view. This alternation should happen while the characteristics of the factory, the processes, the intermediate products and the final product are also studied [25].

Much of the literature points out that a way to increase productive capacity is to enlarge the bottleneck's capacity [22]. The planning of bottleneck expansion should be done considering the following elements:

- how this expansion will affect the processes executed after the bottleneck;

- balance of the new production flow;

- eventual necessity to change the layout;

- particular aspects of the plant. 
The expansion of bottleneck capacity entails significant changes in the performance of a productive process. These changes determine a new flow of materials and intermediate products in the processes close to the bottleneck. They may also affect the entire plant and require a new layout [26]. Such changes need to be balanced according to the new flow of materials. This balancing is achieved by studying the nature and characteristics of the bottleneck, the new material's flow and their relation to the former layout [27]. For the specific case of nuclear fuel factories, any changes in individual processes or layout must be carried out within the safety standards against criticality.

\subsection{Manufacturing modeling and simulation}

Most of the general procedures for productive capacity enlargements are usually found in the literature of operations management [9]. These procedures were adapted for the case of nuclear fuel plants, leading to the establishment of the model presented in Section III.

With regard to the modeling of manufacturing systems, a guide was set to build the simulation model as well as to run the simulation itself. That guide was also established by means of adapting some modeling methodologies found in simulation modeling literature [28].

Simulation modeling guide

1. Problem analysis and information collection;

2. Data collection;

3. Model construction;

4. Model verification and validation;

5. Design and conducting of simulation experiments; and

6. Output analysis

The production of nuclear fuel is a stochastic process, thus allowing for the use of Discrete Events Simulation (DES) [29]. The software employed to run DES in this work was the academic version of ARENA® software [30]. This specific software was chosen because it is one of the most used versions of DES software [31] and because its academic version is available to the University of São Paulo through an agreement with Rockwell Automation. 


\section{MATERIALS AND METHODS}

\subsection{Background}

Real data was gathered from the nuclear fuel factory at IPEN, the Nuclear and Energy Research Institute, located in São Paulo, Brazil [32]. The name "initial situation" was given to the period of data collection at the nuclear fuel plant at IPEN, which happened from March to November of 2014. The initial situation corresponds to scenario 1, as mentioned in the upcoming sections.

\subsection{Nuclear criticality}

In the initial situation, the production lot of the fuel plant at IPEN was based on $3.0 \mathrm{~kg}$ of $\mathrm{UF}_{6}$. That amount was defined because it is considerably less than the critical mass of $\mathrm{UF}_{6}$ [33]. None of the processes of that factory use more than the equivalent uranium mass contained in $3.0 \mathrm{~kg}$ of $\mathrm{UF}_{6}$.

The factory was divided into four Work Centers (WC). The operation mode of the factory requires that one production lot needs to finish its processing in one WC before entering another WC. This way, there are never two production lots within the same WC simultaneously.

The characteristics of safety against criticality [34] of IPEN's factory led to the definition of two important issues of this work:

- the actual production lot, i.e., $3.0 \mathrm{~kg}$ of $\mathrm{UF}_{6}$ is considered;

- focus is given to the route of that production lot through all processes of the plant.

On the other hand, the conceptual model for capacity expansion may change the subcritical condition of an operating factory [35]. For this reason, before putting into practice any of the production settings presented in this technical note, it was necessary to carry out a detailed study of the criticality condition of each production configuration [36]. If that study showed a certain production setting would result in a critical or super-critical condition, that production setting was rejected.

These facts led to the following assumption: each and every production scenario presented in this study is sub-critical. If that assumption had not been taken into account, it would not have been possible to develop all scenarios of this work.

The following model was proposed for enhancing productive capacity:

1. establish organizational and production strategies;

2. identify bottlenecks; 
3. increase the bottleneck's capacity;

4. check for the risk of criticality in the new set up; and

5. check if the demand is met.

\subsection{Process mapping and data gathering}

\subsubsection{Macro view}

In the initial situation, the nuclear fuel plant at IPEN was divided into four work centers (WC), each of which was responsible for carrying out various processes. However, in the macro view, we took each $\mathrm{WC}$ as a single processing unit. Figure 1 shows the macro view of that plant in its initial situation [23]. Figure 1 shows that the nuclear fuel plant at IPEN consisted of three buildings, two of which housed WC 1 and WC 2, respectively, and the third building housed WC 3 and WC 4 . The distance between the buildings was approximately 200 meters.

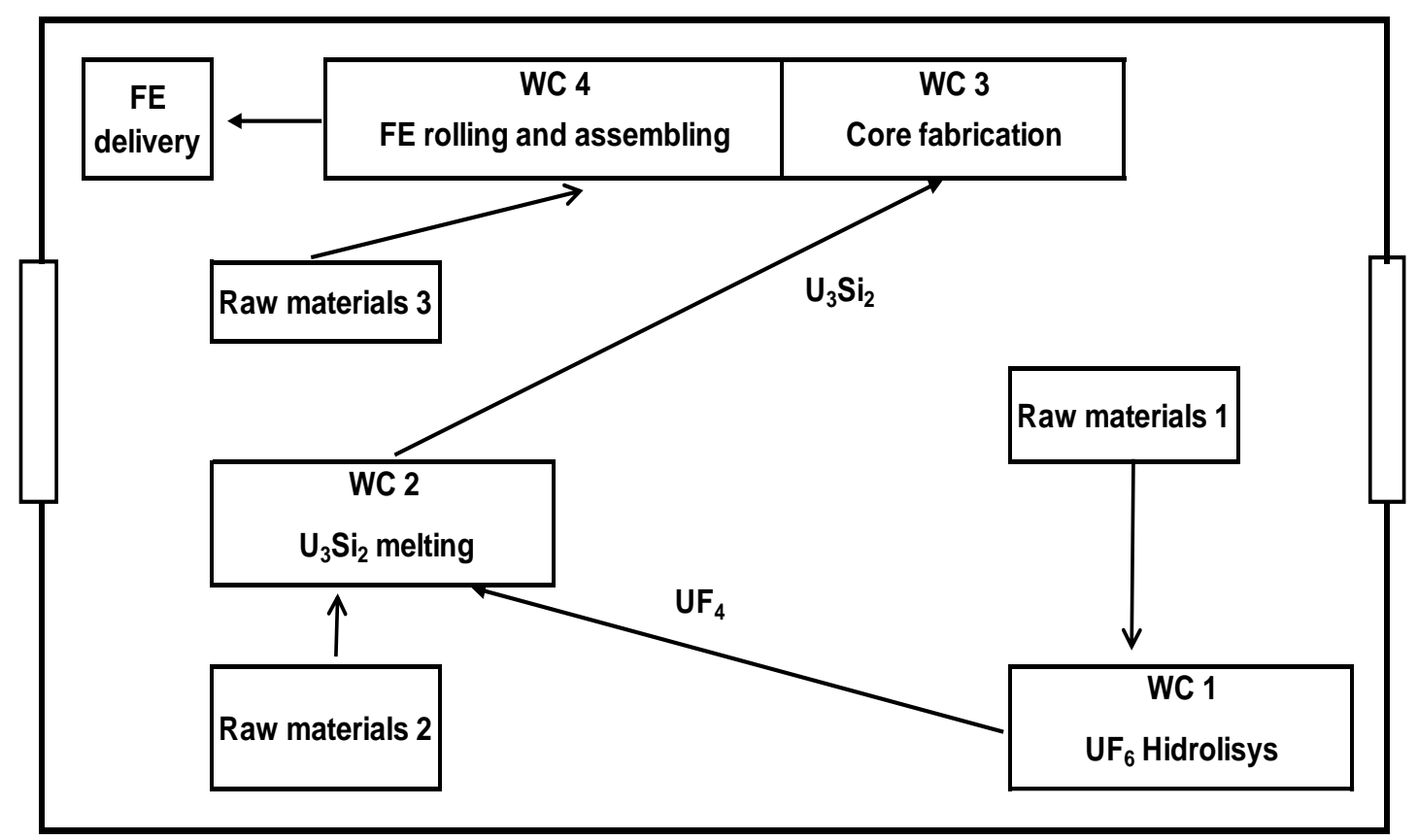

Figure 1: Sketch of the nuclear fuel plant at IPEN

The time taken at a workstation to process one production lot, i.e., the time a production lot needs to be transformed by a certain workstation, is called lead time (L) [37]. Table 1 shows the lead times of the four WCs of the nuclear fuel plant at IPEN in the initial situation. 
Table 1: Lead times of the Work Centers

\begin{tabular}{cccccc}
\hline Work Center - WC & $\mathbf{1}$ & $\mathbf{2}$ & $\mathbf{3}$ & $\mathbf{4}$ & Total \\
Lead time (L) in days & 5.63 & 2.59 & 2.13 & 7.06 & 17.41 \\
\hline
\end{tabular}

The WC with the longest lead time in Table 1 is WC 4. This fact characterizes this WC as the bottleneck of the initial situation. The data in Table 1 allows for the calculation of the production rhythm of the factory in its initial situation. The first four production batches are plotted in the Gantt Chart of Figure 2. In this figure, the very light gray color represents the first production lot; light gray is for the second lot; gray represents the third lot; and black, the fourth.

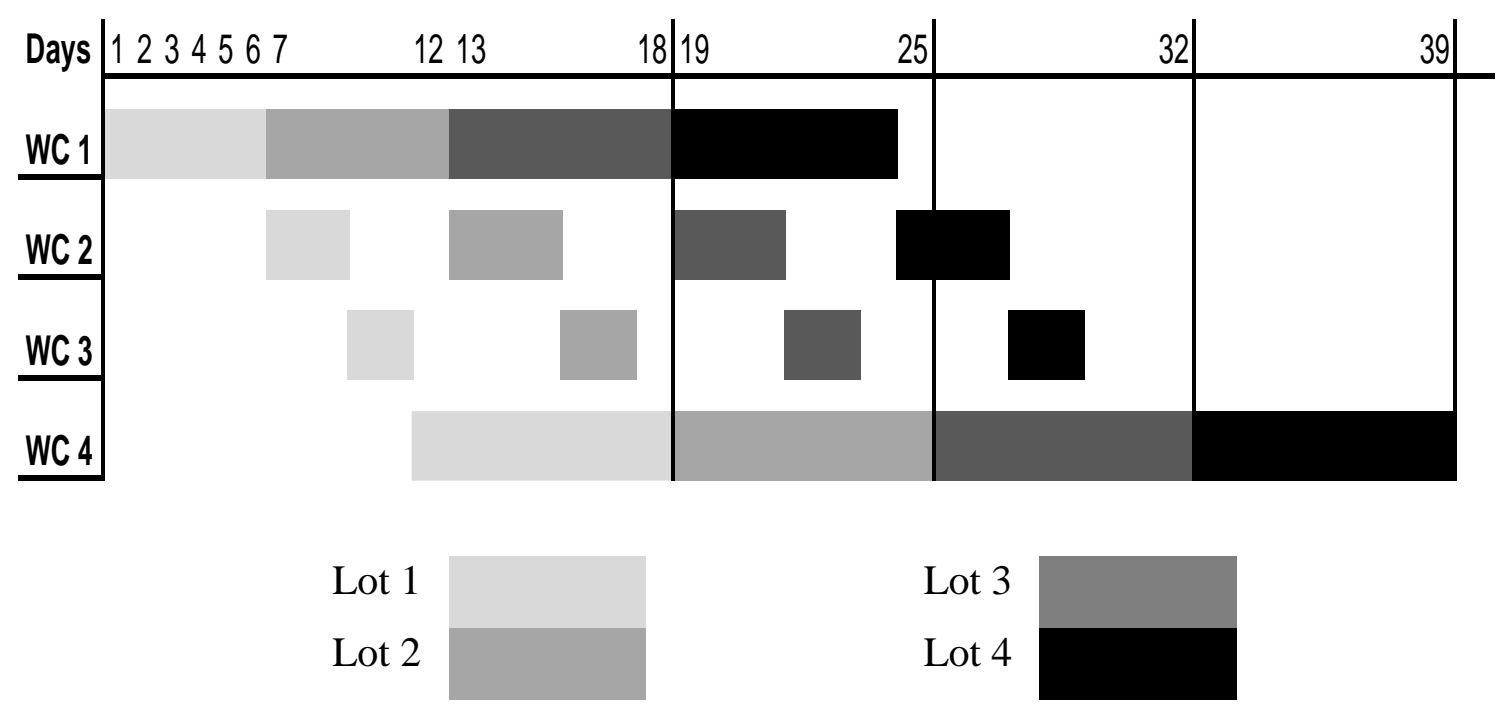

Figure 2: Gantt graph

Source: Authors

Scheduling production as shown in Figure 2 is called forward scheduling [38]. A characteristic of this form of programming is the possible generation of queues, which does happen in this case. The queue of intermediate products increases the risk of criticality, which is one of the reasons for avoiding queues. One way to avoid them is the so-called backward scheduling, illustrated in the Gantt Chart of Figure 3. 




Lot 1

Lot 2



Lot 3

Lot 4

Figure 3: Backward scheduling

Source: Authors

Figure 3 shows no queues of intermediate products. This type of production scheduling works as follows: the first batch is programmed to the bottleneck, and the scheduling of the other batches is subordinated to the bottleneck's scheduling [39]. Backwards scheduling means that more raw material will be left in the storehouse before any processing. This factor is important in a nuclear fuel plant because it contributes to safety against criticality.

Both Figures 2 and 3 show that the first FE is finished on the 18th day of production, the second, on the 25th and so on. This way, an FE is produced every seven working days. This time is generally called cycle time, (C) [20]. Therefore, the total cycle time of this plant in the initial situation was 7 working days.

The graphs of Figures 2 and 3 also make it possible to estimate annual production. To do so, both figures were extended for a total period of one year, yielding the production of $28 \mathrm{FE}$. This result is due to the fact that production only enters into a continuous regime after the 18 th working day.

\subsubsection{Micro view}

The so called micro view [38] considers each process individually. Tables 2 to 5 present all processes performed at the fuel plant at IPEN in the initial situation. 
Table 2: Processes at Work Center 1

\begin{tabular}{llc}
\hline No. & \multicolumn{1}{c}{ Processes } & Time (hours) \\
\hline 1 & Reception of cylinders containing $\mathrm{UF}_{6}$ & 0.80 \\
2 & Preparation for $\mathrm{UF}_{6}$ transfer & 2.45 \\
3 & $\mathrm{UF}_{6}$ transfer from the cylinder to the ampoule & 3.66 \\
4 & ${\text { Preparation for } \mathrm{UF}_{6} \text { hydrolysis }}_{2}$ & 2.54 \\
5 & $\mathrm{UF}_{6}$ hydrolysis & 3.74 \\
6 & ${\text { Preparation for } \mathrm{UF}_{4} \text { precipitation }}_{2}$ & 1.70 \\
7 & $\mathrm{UF}_{4}$ precipitation & 4.28 \\
8 & $\mathrm{UF}_{4}$ washing and filtration & 1.83 \\
9 & $\mathrm{UF}_{4}$ drying & 17.50 \\
10 & $\mathrm{UF}_{4}$ dehydration & 6.50 \\
& TOTAL & 45.00 \\
\hline
\end{tabular}

Table 3: Processes at Work Center 2

\begin{tabular}{llc}
\hline No. & \multicolumn{1}{c}{ Processes } & Time (hours) \\
\hline 11 & Crucible load with $\mathrm{UF}_{4}-\mathrm{Mg}$ & 2.35 \\
12 & $\mathrm{UF}_{4}$ reduction to metallic uranium & 7.28 \\
13 & Crucible disassembly and density measurement & 0.84 \\
14 & Stripping of metallic uranium & 0.56 \\
15 & Crucible load with metallic uranium and $\mathrm{Si}$ & 1.18 \\
16 & Melting of the intermetallic alloy $\mathrm{U}_{3} \mathrm{Si}_{2}$ & 8.20 \\
17 & Density measurement of the $\mathrm{U}_{3} \mathrm{Si}_{2}$ ingot & 0.34 \\
& TOTAL & 20.75 \\
\hline
\end{tabular}

Table 4: Processes at Work Center 3

\begin{tabular}{llc}
\hline No. & \multicolumn{1}{c}{ Processes } & Time (hours) \\
\hline 18 & Grinding of $\mathrm{U}_{3} \mathrm{Si}_{2}$ and powder classification & 1.87 \\
19 & $\mathrm{U}_{3} \mathrm{Si}_{2}$ homogenization with $\mathrm{Al}^{0}$ & 6.28 \\
20 & Pressing of the mix $\mathrm{U}_{3} \mathrm{Si}_{2}$ and $\mathrm{Al}^{0}$ & 2.40 \\
21 & Fuel core dimensional control & 2.76 \\
22 & Fuel core degassing & 3.69 \\
& TOTAL & 17.00 \\
\hline
\end{tabular}


Table 5: Processes at Work Center 4

\begin{tabular}{|c|c|c|}
\hline No. & Processes & Time (hours) \\
\hline 23 & Reception of aluminum boards & 1.67 \\
\hline 24 & Cladding and framing preparation & 3.28 \\
\hline 25 & Cladding and framing stripping & 4.55 \\
\hline 26 & Assembly of the set & 1.12 \\
\hline 27 & Welding of the set & 1.50 \\
\hline 28 & Hot rolling and annealing & 8.83 \\
\hline 29 & Blister inspection & 0.54 \\
\hline 30 & Cold rolling & 1.08 \\
\hline 31 & Initial cut & 3.43 \\
\hline 32 & Four processes on fuel plates (FP) & 8.37 \\
\hline 33 & Final cut & 2.86 \\
\hline 34 & Surface treatment & 2.21 \\
\hline 35 & $\begin{array}{l}\text { Dimensional inspection and second radiography } \\
\text { of FP }\end{array}$ & 3.89 \\
\hline 36 & Scratching test & 1.67 \\
\hline 37 & Stripping of FP and FE components & 6.33 \\
\hline 38 & FE assembly & 6.82 \\
\hline 39 & Quality control & 3.37 \\
\hline 40 & Nozzle fixation & 1.06 \\
\hline 41 & Handling pin fixation & 0.86 \\
\hline 42 & FE dimensional control & 0.96 \\
\hline 43 & FE cleaning and packing & 1.12 \\
\hline \multirow[t]{2}{*}{44} & Delivery of the finished FE & 0.48 \\
\hline & TOTAL & 56.50 \\
\hline
\end{tabular}

\subsection{Traditional strategy}

Traditional strategy is the name given in this work to one way of identifying the bottleneck and increasing its capacity. This strategy is similar to the techniques found in the literature and therefore was denominated as traditional. In this strategy, the macro vision is added to the micro vision. The bottleneck in this strategy is identified by means of the following two steps: 
Step A. Look for the WC with the longest processing time, that is, identify the bottleneck using the macro view, and

Step B. Look for the process with the longest processing time within the WC defined in Step A, according to the micro view.

According to this strategy, one can identify the bottleneck of IPEN's nuclear fuel factory in its initial situation within WC 4. This is process 28 , Hot rolling and annealing, from Table 5 .

As for the increase in the capacity of the bottleneck, it is assumed that the traditional strategy doubles that capacity. This increase in capacity is usually achieved through the acquisition of new equipment [35]. Addressing details on how to expand this capability would go beyond the scope of this work. The same applies for the cost of purchasing new equipment. Doubling the capacity of the bottleneck has two effects:

- the bottleneck process is executed in half the time, and

- the total processing time is decreased.

\subsection{Division strategy}

The observation of IPEN's nuclear fuel factory during data collection yielded another idea: increasing production could be done by the division of work centers. Such a division would be possible by using other spaces and assuring that processes remained safe against criticality. That idea was developed into another strategy, called "division strategy." This name was chosen because this strategy increases the bottleneck's capacity by means of the division of a WC.

The division strategy is based on the macro view; in other words, the bottleneck is determined by searching for the WC with the highest lead time in a given production configuration. For the initial situation of IPEN's factory, the division strategy identified the bottleneck as the WC with the highest lead time in Table 1, which is WC 4.

This strategy establishes that the capacity of the bottleneck will be increased by dividing the whole WC identified as the bottleneck. The division of a WC is possible because in each WC several production processes are performed, but each process can be performed separately. The way to divide WCs and the criteria adopted for this division using the division strategy are as follows:

- find the balance between the sums of the lead times of the resulting WCs;

- do not divide processes that use the same equipment; and

- keep process sequencing. 
The balance between the total lead times of the new WCs corresponds to the capacity increase factor of the original WC. Thus, the better this balance, the larger is the increase of the bottleneck's capacity.

We assume that the WC resulting from the division is safe against criticality, as mentioned earlier. This allows a production batch to be processed in one of the new WCs at the same time that another batch is being processed in the new WC, which resulted from the division of the original WC.

It is important to note that in the division strategy there is no change in individual processes. Therefore, the sum of the lead times of the new WCs corresponds to the lead time of the WC that originated them. Likewise, the total lead time of the plant is always the same. In the case of the nuclear fuel plant at IPEN, the total lead time is 17.41 business days, as shown in Table 1.

It is important to point out that the division strategy keeps all equipment available that was present in the initial status, but it requires relocation of that equipment. The cost of relocating existing equipment is assumed to be lower than that of purchasing new equipment. It was not possible to go into further details about cost as there was a lack of such data for this work.

\subsection{Scenarios}

In this study, the term "scenario" refers to a certain production configuration. Scenario 1 corresponds to the production configuration of the nuclear fuel plant at IPEN in its initial situation. The increase in the capacity of the bottleneck, the new flow of materials resulting therefrom, the eventual new physical arrangement, and the new level of production characterize a new production configuration, i.e., a new scenario. The main change between a scenario and its subsequent one is the increase of the bottleneck's capacity. The numbering of the scenarios is ascending. Thus, high scenario numbers correspond to production configurations with higher productive capacity than low scenario numbers. Table 6 presents the hypotheses valid for all scenarios.

Hypotheses 2, 3 and 4 were adopted because of insufficient data regarding quality and labor. Hypotheses 1,5 and 6 are contour conditions in addition to the organization and production strategies [40]. Scenario generation was done by the execution of following steps:

1. scenario in which the bottleneck and the annual production are known;

2. increase the bottleneck's capacity;

3. measure the new capacity;

4. apply DES simulation for the enlarged capacity; 
5. take note of the new yearly production returned by the DES;

6. return to step 1 with the data generated in steps 3 and 5 .

Figure 4 shows the dynamics for replication of steps 1 to 6 .

Table 6: Hypothesis applied to all scenarios

\begin{tabular}{cc}
\hline Nr. & Hypothesis \\
\hline 1 & $\mathrm{UF}_{6}$ supply is continuous and sufficient; \\
2 & $\mathrm{UF}_{6}$ quality is enough to operate all processes; \\
3 & There is no loss due to quality throughout the factory; \\
4 & Labor is sufficient and is trained to carry out all processes; \\
5 & Production time is 210 workdays per year, that is, approximately ten months of \\
6 & oproduction. \\
7 & There is demand for FE for any increase in capacity.
\end{tabular}

Scenario of which we know the bottleneck and yearly production
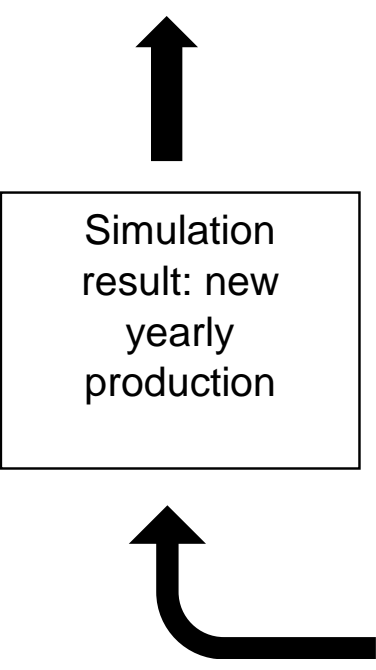


DES simulation
Enlargement of the bottleneck's capacity

Figure 4: Scenario generation and simulation

Source: Authors 
Steps 1 to 6 were replicated fifteen times for the traditional strategy and seven times for the division strategy. In other words, fifteen scenarios were generated for the traditional strategy and seven for the division strategy. Both strategies start from the initial situation, i.e., scenario 1.

Simulation models were built for each scenario, and all simulation models were run on Discrete Event Simulation (DES) with the software ARENA ${ }^{\circledR}$ [30] for each scenario. One of the simulation's results is the yearly production, given in number of FE per year. That is the value used to generate the next scenario, as per step 5 above.

a) Scenarios of the traditional strategy

As mentioned, this strategy halves the process time of the bottleneck. This new time is then assigned to the bottleneck, a fact that generates the next scenario. Thus, scenario 2 includes the widening of the bottleneck of scenario 1 , scenario 3 includes the expansion of the bottleneck of scenario 2, and so on. The replication of this strategy was stopped in scenario 16 because the average production increase of this strategy is smaller than the one of the division strategy. Thus, the numbers of the scenarios for the traditional strategy range from 2 to 16.

b) Scenarios of the division strategy

As mentioned, this strategy divides the WC considered the bottleneck. The division of this WC increases its capacity, which generates the next scenario. The ascending numbering of the scenarios was kept in order to make their identification clearer. Thus, scenario 17 incorporates the expansion of the bottleneck's capacity of scenario 1, as provided by the division strategy. Scenario 18 includes the widening of the bottleneck of scenario 17, and so on. A division of a WC in scenario 23 yields a smaller production increase than increasing the bottleneck capacity of an isolated process. However, altering a single process diverges from the division strategy. That fact led to halting iterations of this strategy in scenario 23 . Thus, the numbering of scenarios by the division strategy range from 17 to 23 .

\section{RESULTS AND DISCUSSION}

\subsection{Traditional strategy}

This strategy halves the processing time of the bottleneck. This reduction leads to a reduction in the lead time of the WC where the bottleneck is located as well as in the total 
lead time of the plant. That contraction was added to the subsequent scenario. This way, each reduction of lead time generated a new scenario. Table 7 presents the values resulting from the application of this procedure as well as a striking characteristic of the traditional strategy, which is to keep all four WCs equal in number in any scenario, i.e., four WCs. Therefore, in this strategy the differences from one scenario to the next are the reduction in the bottleneck's lead time and in the total lead time of the plant.

Table 7: Lead times according to the traditional strategy in working days

\begin{tabular}{cccccc}
\hline Scenario & WC 1 & WC 2 & WC 3 & WC 4 & Factory \\
\hline 1 & 5.63 & 2.59 & 2.13 & 7.06 & 17.41 \\
2 & 5.63 & 2.59 & 2.13 & 6.51 & 16.86 \\
3 & 5.63 & 2.59 & 2.13 & 5.99 & 16.34 \\
4 & 5.63 & 2.59 & 2.13 & 5.56 & 15.91 \\
5 & 4.53 & 2.59 & 2.13 & 5.56 & 14.81 \\
6 & 4.53 & 2.59 & 2.13 & 5.17 & 14.42 \\
7 & 4.53 & 2.59 & 2.13 & 4.89 & 14.14 \\
8 & 4.53 & 2.59 & 2.13 & 4.62 & 13.87 \\
9 & 4.53 & 2.59 & 2.13 & 4.38 & 13.63 \\
10 & 3.98 & 2.59 & 2.13 & 4.38 & 13.08 \\
11 & 3.98 & 2.59 & 2.13 & 4.17 & 12.87 \\
12 & 3.98 & 2.59 & 2.13 & 3.95 & 12.65 \\
13 & 3.58 & 2.59 & 2.13 & 3.95 & 12.25 \\
14 & 3.58 & 2.59 & 2.13 & 3.74 & 12.04 \\
15 & 3.58 & 2.59 & 2.13 & 3.54 & 11.84 \\
16 & 3.30 & 2.59 & 2.13 & 3.54 & 11.56 \\
\hline
\end{tabular}

\subsection{Division strategy}

The division strategy increases the capacity of the WC considered the bottleneck by disassembling it so that there are two WCs where there was once only one. This way, the main difference from one scenario to the next is the addition of a WC. An important feature of the division strategy is that all scenarios have the same lead time, as there are no changes in individual processes. Therefore, the sum of lead times of all WCs is the same in all scenarios of this strategy and results in 17.41 business days. These facts generated the data presented in Table 8. 
Table 8: Scenario data according to the division strategy

\begin{tabular}{|c|c|c|c|c|c|c|c|c|c|c|c|c|c|}
\hline Scenario & WC & nber & & & $\mathrm{C} 1$ & & & 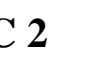 & WC 3 & & & 4 & \\
\hline \multirow{2}{*}{1} & \multirow{2}{*}{4} & WC & 1 & & & & 2 & & 3 & 4 & & & \\
\hline & & $\mathrm{L}$ & 5.63 & & & & 2.9 & & 2.13 & 7.06 & & & \\
\hline \multirow{2}{*}{17} & \multirow{2}{*}{5} & WC & 1 & & & & 2 & & 3 & 4.1 & 4.2 & & \\
\hline & & $\mathrm{L}$ & 5.63 & & & & 2.59 & & 2.13 & 3.47 & 3.60 & & \\
\hline \multirow{2}{*}{18} & \multirow{2}{*}{6} & WC & 1.1 & 1.2 & & & 2 & & 3 & 4.1 & 4.2 & & \\
\hline & & $\mathrm{L}$ & 2.63 & 3.00 & & & 2.59 & & 2.13 & 3.47 & 3.60 & & \\
\hline \multirow{2}{*}{19} & \multirow{2}{*}{7} & WC & 1.1 & 1.2 & & & 2 & & 3 & 4.1 & 4.2 & 4.3 & \\
\hline & & $\mathrm{L}$ & 2.63 & 3.00 & & & 2.59 & & 2.13 & 2.06 & 2.38 & 2.63 & \\
\hline \multirow{2}{*}{20} & \multirow{2}{*}{8} & WC & 1.1 & 1.2 & 1.3 & & 2 & & 3 & 4.1 & 4.2 & 4.3 & \\
\hline & & $\mathrm{L}$ & 2.4 & 2.42 & 0.81 & & 2.59 & & 2.13 & 2.06 & 2.38 & 2.63 & \\
\hline \multirow{2}{*}{21} & \multirow{2}{*}{9} & WC & 1.1 & 1.2 & 1.3 & & 2 & & 3 & 4.1 & 4.2 & 4.3 & 4.4 \\
\hline & & $\mathrm{L}$ & 2.4 & 2.42 & 0.81 & & 2.59 & & 2.13 & 1.63 & 1.83 & 1.76 & 1.83 \\
\hline \multirow{2}{*}{22} & \multirow{2}{*}{10} & WC & 1.1 & 1.2 & 1.3 & & 2.1 & 2.2 & 3 & 4.1 & 4.2 & 4.3 & 4.4 \\
\hline & & $\mathrm{L}$ & 2.4 & 2.42 & 0.81 & & 1.30 & 1.29 & 2.13 & 1.63 & 1.83 & 1.76 & 1.83 \\
\hline \multirow{2}{*}{23} & \multirow{2}{*}{11} & WC & 1.1 & 1.2 & 1.3 & 1.4 & 2.1 & 2.2 & 3 & 4.1 & 4.2 & 4.3 & 4.4 \\
\hline & & $\mathrm{L}$ & 1.86 & 0.76 & 2.19 & 0.81 & 1.30 & 1.29 & 2.13 & 1.63 & 1.83 & 1.76 & 1.83 \\
\hline
\end{tabular}




\subsection{Results of discrete events simulation (DES)}

Data from Tables 7 and 8 was used as input to run respective simulation models in ARENA ${ }^{\circledR}$.

\section{Scenario 1}

As mentioned before, the initial configuration of the nuclear fuel plant at IPEN is called scenario 1 , which is represented in Tables 2 to 5 . The simulation of this scenario in ARENA ${ }^{\circledR}$ resulted in a production of $28 \mathrm{FE}$ per year. The bottleneck identified in this scenario according to the traditional strategy is hot rolling and annealing, which is process 28 of WC 4 . According to the division strategy, the bottleneck is also WC 4 . These results for scenario 1 concur with the ones obtained by means of the Gantt charts from section 3. That concurrence proves that the simulation model in ARENA ${ }^{\circledR}$ is correct.

Once the annual production and the bottleneck of scenario 1 were known, it was then possible to advance to the next scenario. That was done by means of applying both the traditional strategy and the division strategy, as set out below.

\subsubsection{Traditional strategy}

Scenarios 2 to 16

This strategy was initially applied to scenario 1, and it enlarged the bottleneck's capacity of each scenario by doubling it. Thus, new cycle times, new annual productions and new bottlenecks were found. These results are presented in Table 9. The average production increase between the scenarios in Table 9 is $4.6 \%$. That is considered a small increase, due to the observations made in person during the work at the factory. It also changes little regardless of the number of scenarios generated. In addition, it is often necessary to purchase new equipment for the capacity enhancements promoted by the traditional strategy.

\subsubsection{Division Strategy}

Scenarios 17 to 23

This strategy was also applied to scenario 1 and data from Table 8 was used to run DES in ARENA $^{\circledR}$. Thus, new cycle times, new annual productions and new bottlenecks were found. These results are presented in Table 10. 
Table 9: DES results of the traditional strategy

\begin{tabular}{|c|c|c|c|c|c|c|}
\hline \multirow{2}{*}{ Scenario } & \multicolumn{2}{|l|}{ Bottleneck } & \multirow{2}{*}{$\begin{array}{l}\text { Total } \\
\text { cycle } \\
\text { time } \\
\text { (days) }\end{array}$} & \multirow{2}{*}{$\begin{array}{c}\text { Production } \\
\text { (FE per year) }\end{array}$} & \multicolumn{2}{|c|}{$\begin{array}{l}\text { Percentage rise } \\
\text { regarding }\end{array}$} \\
\hline & Process & Nr. & & & $\begin{array}{l}\text { Previous } \\
\text { scenario }\end{array}$ & $\begin{array}{c}\text { Scenario } \\
1\end{array}$ \\
\hline 1 & Hot rolling & 28 & 7.5 & 28 & - & - \\
\hline 2 & Four processes & 32 & 7.0 & 30 & 7 & 7 \\
\hline 3 & FE assembly & 38 & 6.4 & 33 & 10 & 18 \\
\hline 4 & $\mathrm{UF}_{4}$ drying & 9 & 6.2 & 34 & 3 & 21 \\
\hline 5 & Stripping & 37 & 5.8 & 36 & 6 & 29 \\
\hline 6 & Hot rolling & 28 & 5.5 & 38 & 6 & 36 \\
\hline 7 & Four processes & 32 & 5.3 & 40 & 5 & 43 \\
\hline 8 & Dimensional control & 35 & 5.0 & 42 & 5 & 50 \\
\hline 9 & $\mathrm{UF}_{4}$ drying & 9 & 5.0 & 42 & 0 & 50 \\
\hline 10 & Initial cut & 31 & 4.7 & 45 & 7 & 61 \\
\hline 11 & FE assembly & 38 & 4.5 & 47 & 4 & 68 \\
\hline 12 & $\mathrm{UF}_{4}$ dehydration & 10 & 4.4 & 48 & 2 & 71 \\
\hline 13 & Quality control & 39 & 4.2 & 50 & 4 & 79 \\
\hline 14 & Stripping & 37 & 4.0 & 52 & 4 & 86 \\
\hline 15 & $\mathrm{UF}_{4}$ drying & 9 & 4.0 & 53 & 2 & 89 \\
\hline 16 & Final cut & 33 & 3.8 & 55 & 4 & 96 \\
\hline
\end{tabular}

Table 10 contains data of higher rises in production than table 9, thus revealing a more efficient means of raising productive capacity. However, the highest values of the last two tables are displayed in table 11 in order to make that difference clearer. 
Table 10: DES results of the division strategy

\begin{tabular}{|c|c|c|c|c|c|}
\hline \multirow{2}{*}{ Scenario } & \multirow{2}{*}{ Bottleneck } & \multirow{2}{*}{$\begin{array}{c}\text { Total cycle } \\
\text { time } \\
\text { (days) }\end{array}$} & \multirow{2}{*}{$\begin{array}{c}\text { Production } \\
\text { (FE per } \\
\text { year) }\end{array}$} & \multicolumn{2}{|c|}{$\begin{array}{c}\text { Percentage rise } \\
\text { regarding }\end{array}$} \\
\hline & & & & $\begin{array}{l}\text { Previous } \\
\text { scenario }\end{array}$ & $\begin{array}{c}\text { Scenario } \\
1\end{array}$ \\
\hline 1 & WC 4 & 7.5 & 28 & - & - \\
\hline 17 & WC 1 & 6.0 & 35 & 25 & 25 \\
\hline 18 & WC 4 & 4.0 & 53 & 51 & 89 \\
\hline 19 & WC 1 & 3.3 & 64 & 21 & 129 \\
\hline 20 & WC 4 & 3.0 & 71 & 11 & 154 \\
\hline 21 & WC 2 & 2.8 & 75 & 6 & 168 \\
\hline 22 & WC 1 & 2.7 & 78 & 4 & 179 \\
\hline 23 & Not applicable & 2.4 & 86 & 10 & 207 \\
\hline
\end{tabular}

Table 11: Comparison of results

\begin{tabular}{cccc}
\hline Strategy & $\begin{array}{c}\text { Number of } \\
\text { scenarios }\end{array}$ & $\begin{array}{c}\text { Maximal production } \\
\text { (FE per year) }\end{array}$ & $\begin{array}{c}\text { Production } \\
\text { rise }\end{array}$ \\
\hline Traditional & 15 & 55 & $96 \%$ \\
Division & 7 & 86 & $207 \%$ \\
\hline
\end{tabular}

Table 11 shows that both strategies enlarge the production capacity. It also shows that the division strategy yields a larger increase and requires fewer changes than the traditional strategy. Production rise in Table 11 was calculated in relation to scenario 1.

\subsection{Trade-offs}

The qualitative information from all previous sections allows to build the following basic tradeoffs reasoning. It is a fact that IPEN's factory has the sufficient number of workers to run the 
division strategy. This means that processes being executed simultaneously would not be affected by lack of labor. This also means that labor costs would not increase due to the division strategy. For the traditional strategy, however, there would be some expenses for training the workforce in the use of the new equipment.

Furthermore, safety against criticality demands that processes split by the Division Strategy be executed with safe physical distance one from another. However, we know that IPEN's factory has sufficient idle space to shelter all processes split by the division strategy. This means that there would be no cost for providing new housing for the split processes. The same applies for the new equipment bought by the traditional strategy.

Both strategies require the installation of equipment, i.e., new purchased equipment for the traditional strategy and the displaced equipment for the division strategy.

Table 12 summarizes the facts above. In this table, the issues demanded by each strategy are signaled with an " $\mathrm{X}$ ".

Table 12: Basic trade offs

\begin{tabular}{ccc}
\hline Topic / Strategy & Traditional & Division \\
Installation & $\mathrm{X}$ & $\mathrm{X}$ \\
Construction & & \\
Labor training & $\mathrm{X}$ & \\
Equipment Purchase & $\mathrm{X}$ & \\
Capacity increase $(\%)$ & 96 & 207 \\
\hline
\end{tabular}

\section{CONCLUSION}

This article had the objective of proposing and testing a conceptual model for expanding the production capacity of fuel plants for nuclear research reactors. A model was established, proposed and tested by means of a case study of the nuclear fuel plant at IPEN. The model proved to be flexible because it worked well under two different strategies of execution. 
Both strategies for increasing production capacity proved to be effective in increasing the total capacity of the plant. The traditional strategy generated up to a $96 \%$ increase, whereas the division strategy yielded an increase of up to $207 \%$. Therefore, the division strategy produced larger increases than the traditional strategy. The comparison of annual production between scenarios 1 and 23 shows that it is possible to produce three times more than in the initial situation by simply relocating processes, without the need of purchasing new equipment. This increase in production capacity leads to an increase in production and a decrease in the total plant cycle time. Considering the case study covered, total plant cycle time decreases from 7.0 to 2.44 working days.

A basic approach to trade-offs indicates that the division strategy does not have the cost of purchasing new equipment and yields higher production. The higher production would always be sold, according to the assumptions made in this work. That fact increases the revenue on a larger scale than the traditional strategy. Thus, trade-off is favorable to the division strategy.

The indicated changes are relevant because the production capacity of some facilities that produce nuclear fuel for research reactors is not enough to meet the current demand for such fuel. Thus, the conclusions are significant for the administrators of these installations, making the present research a relevant contribution.

Regarding future works, the present model provides the basis for the aggregation of studies from some areas that have impacts on the expansion of productive capacity. Safety and costs stand out among these areas. The association of studies of these areas with the model developed in this work will allow for the elaboration of other simulation models.

\section{REFERENCES}

[1] SEKIMOTO, H. Nuclear reactor theory. Tokyo, Japan: Tokyo Institute of Technology, 2007.

[2] GIRALDO, J.S.; GOTHAM, D.J.; ET AL. Fundamentals of Nuclear Power. n. December, p. 1-67, 2012.

[3] WRIGHT, C.L.; MALY, J.J.; ET AL. Advancing Precision Nuclear Medicine and Molecular Imaging for Lymphoma. PET Clinics, v. 12, n. 1, p. 63-82, 2016. 
[4] ALMAZ, E.; STONE, S.; ET AL. The effects of neutron irradiation and low temperature annealing on the electrical properties of highly doped $4 \mathrm{H}$ silicon carbide. Nuclear Instruments and Methods in Physics Research, Section A: Accelerators, Spectrometers, Detectors and Associated Equipment, v. 622, n. 1, p. 200-206, 2010.

[5] HUSEYNOV, E.M. Investigation of the agglomeration and amorphous transformation effects of neutron irradiation on the nanocrystalline silicon carbide (3C-SiC) using TEM and SEM methods. Physica B: Condensed Matter, v. 510, n. December 2016, p. 99-103, 2017.

[6] CHENG, X.; BATTA, A.; ET AL. European activities on crosscutting thermal-hydraulic phenomena for innovative nuclear systems. Nuclear Engineering and Design, v. 290, p. $2-$ $12,2015$.

[7] ZHANG, H.; CHENG, H.; ET AL. Thirty meters small angle neutron scattering instrument at China advanced research reactor. Nuclear Instruments and Methods in Physics Research, Section A: Accelerators, Spectrometers, Detectors and Associated Equipment, v. 735, p. 490495, 2014.

[8] HONG, S.; BRADSHAW, C.J.A.; ET AL. Nuclear power can reduce emissions and maintain a strong economy: Rating Australia's optimal future electricity-generation mix by technologies and policies. Applied Energy, v. 136, p. 712-725, 2014.

[9] CERCHIONE, R.; ESPOSITO, E. A systematic review of supply chain knowledge management research: State of the art and research opportunities. International Journal of Production Economics, v. 182, p. 276-292, 2016.

[10] SNElgrove, J.L.; DORAaGALA, R.F.; ET AL. The Use of $\mathbf{U}_{\mathbf{3}} \mathbf{S i}_{2}$ Dispersed in Aluminum in Plate-type Fuel Elements for Research and Test Reactors. Argonne, IL: 1987.

[11] DURAZZO, M.; RIELLA, H.G. Procedures for Manufacturing Nuclear Research Reactor Fuel Elements. Saarbrücken, Germany: OmniScriptum GmbH \& Co. KG, 2015. 
[12] CHANDLER, D. ET AL. Neutronic and thermal-hydraulic feasibility studies for High Flux Isotope Reactor conversion to low-enriched uranium silicide dispersion fuel. Annals of Nuclear Energy, v. 130, n. August 2019, p. 277-292, 2019.

[13] LERAY, O. ET AL. Neutronics qualification of the Jules Horowitz Reactor fuel by interpretation of the VALMONT experimental program - Transposition of the uncertainties on the reactivity of JHR with JEF2.2 and JEFF3.1.1. In: 2ND INTERNATIONAL CONFERENCE ON ADVANCEMENTS IN NUCLEAR INSTRUMENTATION, MEASUREMENT METHODS AND THEIR APPLICATIONS. Ghent, Belgium: 2011, p. $1-8$.

[14] SCANNEN, L. Scientific report. Mol, Belgium: 2004.

[15] SAliBA-SIlvA, A.M.; CARVAlHO, E.F.U. DE; ET AL. Research Reactor Fuel Fabrication to Produce Radioisotopes. Radioisotopes-Applications in Physical Sciences: InTech, 2011.

[16] GAN, J.; KEISER, D.D.; ET AL. Microstructure of the irradiated U3Si2/Al silicide dispersion fuel. Journal of Nuclear Materials, v. 419, n. 1-3, p. 97-104, 2011.

[17] NEGRO, M.L.M.; DURAZZO, M.; ET AL. Studies on Capacity Expansion of Fuel Plants for Nuclear Research Reactors. World Journal of Nuclear Science and Technology, v. 08, n. 02, p. 38-53, 2018.

[18] KIM, Y.S.; HOFMAN, G.L.; ET AL. Temperature and dose dependence of fission-gas-bubble swelling in U3Si2. Journal of Nuclear Materials, v. 389, n. 3, p. 443-449, 2009.

[19] SIMNAD, M.T. Perspective on Research Reactors and Their Fuel Elements. Journal of Nuclear Materials, v. 100, p. 78-92, 1981.

[20] CHOI, S.; MESSINGER, P.R. The role of fairness in competitive supply chain relationships: An experimental study. European Journal of Operational Research, v. 251, n. 3, p. 798813, 2014. 
[21] QIN, F.; MAI, F.; ET AL. Supply-chain performance anomalies: Fairness concerns under private cost information. European Journal of Operational Research, v. 252, n. 1, p. 170 $182,2016$.

[22] GOLDRATT, E.M.; COX, J. The goal. Great Barrington, MA: 2004.

[23] KRAJEWSKI, L.J.; MALHOTRA, M.K.; ET AL. Operations Management: Processes and Supply Chains Plus. Upper Saddle River, New Jersey, USA: Prentice Hall, 2015.

[24] BALAMAN, Ş.Y. Investment planning and strategic management of sustainable systems for clean power generation: An $\varepsilon$-constraint based multi objective modelling approach. Journal of Cleaner Production, v. 137, p. 1179-1190, 2016.

[25] ZHU, Q.; FENG, Y.; ET AL. The role of customer relational governance in environmental and economic performance improvement through green supply chain management. Journal of Cleaner Production, p. 27, 2016.

[26] TSENG, M.-L.; LIM, M.K.; ET AL. A framework for evaluating the performance of sustainable service supply chain management under uncertainty. International Journal of Production Economics, n. 2012, 2016.

[27] BROCKE, J. VOM; ZELT, S.; ET AL. On the role of context in business process management. International Journal of Information Management, v. 36, n. 3, p. 486-495, 2016.

[28] DiAllo, S.; MUSTAFEE, N. Towards an Encyclopedia of Modeling and Simulation Methodology. n. 2003, p. 2692-2703, 2015.

[29] BARIL, C.; GASCON, V.; ET AL. Use of a discrete-event simulation in a Kaizen event: A case study in healthcare. European Journal of Operational Research, v. 249, n. 1, p. 327 339, 2016.

[30] Rockwell Automation (2015). Arena Simulation Software.

[31] DIAS, L.M.S., PEREIRA, G.A.B., VIK, P., \& OLIVEIRA, J.A. (2011). Discrete Simulation Tools Ranking. 6. 
[32] SILVA, A.T.; TERREMOTO, L.A.A.; ET AL. Qualification program of research reactor fuels manufactured at IPEN e CNEN / SP. v. 50, p. 795-799, 2008.

[33] PRUVOST, N.L.; PAXTON, H.C. Nuclear Criticality Safety Guide. Los Alamos, CA: 1996.

[34] WOO, S.M.; BOO, H.; ET AL. Investigations on Detecting Potential Nuclear Material Diversion from a Pyroprocessing Facility Investigations on Detecting Potential Nuclear Material Diversion from a Pyroprocessing Facility. Nuclear Technology, v. 205, n. 3, p. 464473, 2019.

[35] HODGES, M.S.; SANDERS, C.E. Nuclear criticality accident safety, near misses and classification. Elsevier Ltd, 2014.

[36] SHUGART, N.; KING, J.; ET AL. Examining Fuel-Cycle Scenarios with the Safeguards Analysis Toolbox Examining Fuel-Cycle Scenarios with the Safeguards Analysis Toolbox. Nuclear Technology, v. 204, n. 2, p. 147-161, 2018.

[37] PINEDO, M.L. Scheduling. New York, NY: Springer Science+Business Media, LLC, 2008.

[38] PINEDO, M.L. Planning and Scheduling in Manufacture and Services. New York, NY: Springer, 2005.

[39] CERDAS, F.; KURLE, D.; ET AL. ScienceDirect Defining Circulation Factories - A pathway towards Factories of the Future. Procedia CIRP, v. 29, p. 627-632, 2015.

[40] HEDAYAT, A. Developing a practical optimization of the refueling program for ordinary research reactors using a modified simulated annealing method. Progress in Nuclear Energy, v. 76, p. 191-205, 2014. 